\title{
A INFLUÊNCIA DA ORGANIZAÇÃO TEXTUAL NA COMPREENSÃO LEITORA
}

\author{
THE INFLUENCE OF ORGANIZATION TEXTUAL UNDERSTANDING THE READER
}

\section{BLANK, Soraia Cristina}

\begin{abstract}
Resumo
Neste trabalho, buscamos avaliar a compreensão leitora dos indivíduos frente a diferentes formas de organização textuais. Com base na teoria dos processos cognitivos da leitura de Kleiman (2004), na definição das características hipertextuais do texto de Marcuschi (1999, 2001, 2005, 2007), levantamos a hipótese de que a organização hipertextual com seus recursos hipermidiáticos influenciaria o processo de compreensão leitora e produziria diferentes resultados de compreensão leitora em relação à versão linear. Para verificar se a organização textual interfere no processamento da leitura, foram produzidos dois experimentos. Para cada um deles foi construída uma versão hipertextual e outra idêntica em versão linear. Após a leitura dos textos, os informantes foram submetidos a um questionário que objetivava avaliar importantes habilidades de leitura, a saber: compreensão global/tema, localização de informação explícita, inferência de informação implícita, estabelecimento de relações de coerência local e estabelecimento de relações de coerência entre links.
\end{abstract}

Palavras-chave: Compreensão. Hipertexto. Leitura

\begin{abstract}
In this paper we evaluate the reading comprehension of individuals against different forms of textual organization. Based on the theory of the cognitive processes of reading Kleiman (2004), in defining the characteristics of hypertext text Marcuschi (1999, 2001, 2005, 2007) hypothesized that the hypertextual organization with its resources hypermedia influence the process reading comprehension and produce different outcomes in relation to reading comprehension linear version. To check whether the textual organization interferes with the processing of reading, two experiments were produced. For each one of them was built a hypertext version and another version in identical linear. After reading the texts, the informants were subjected to a questionnaire that aimed to assess important reading skills, namely: understanding global / theme, location information explicit, implicit inference of information, establishment of relations of local coherence and establishing relationships coherence between links.

Keywords: Comprehension. Hypertext. Reading.

1 - PHD em linguística, é Doutora em Psicanálise, cuja pesquisa está voltada para Psicanálise e Linguagem, possui Mestrado em Letras- Lingüística Aplicada, ênfase em teorias de aquisição de segundas línguas pela UFPR e graduação em Letras Português Espanhol pela Universidade Federal do Paraná (2002). Tem experiência na área de Lingüística, com ênfase em Lingüística Aplicada. É especialista em Psicopedagogia Clínica e Institucional e Ensino-Aprendizagem de Língua Espanhola e suas Literaturas. É professora de língua portuguesa, língua espanhola e literatura, além de desenvolver projeto na área de aquisição de léxico a partir de textos (especificamente voltado à área de aquisição de língua espanhola). E-mail: soraiablank@ifto.edu.br
\end{abstract}




\section{DIVERS@!}

\section{1 - INTRODUÇÃO}

A forma de lidar com a informação mudou radicalmente, quando comparamos a utilização dos pergaminhos, seguido da organização em livros, com tópicos separados por capítulos e instituição de um índice, que levava o leitor direto a uma informação sem a necessidade da leitura integral da obra. Depois vieram os livros digitais e então chegamos à estrutura hipertextual, com capacidade de nos levar instantaneamente a diferentes tópicos em infinitos textos com uma multiplicidade de mídias, o que torna a leitura mais produtiva e agradável. Isso nos faz refletir sobre nossas concepções de leitura, compreensão e produção textual, bem como é inegável que esses recursos tecnológicos modificaram e modificarão ainda mais nossa experiência com textos, bem como a sua produção nesses novos suportes.

Esse trabalho focalizará a investigação da influência da organização (linear e hipertextual) na compreensão leitora.

Para esse intento, temos como objetivos: verificar as variáveis de compreensão leitora quando confrontadas as versões linear e hipertextual do experimento, via questionário de avaliação submetida aos informantes; investigar o tempo de leitura entre as versões linear e hipertextual; entender os caminhos dentro da malha hipertextual trilhados pelos informantes submetidos à versão hipertextual em ambos os experimentos; determinar as potencialidades e as abordagens possíveis quando da utilização de hipertextos em comparação aos textos lineares.

Essa investigação justifica-se por acreditarmos que a organização textual possibilite um melhor índice da compreensão leitora em relação ao formato linear e que a mudança de conteúdo gere diferentes modelos de compreensão. Como pesquisas relevantes nessa área, citamos o trabalho de Coscarelli (2005), em que se investigou o papel da organização textual baseada em imagens na construção adequada do hipertexto e compreensão comparada à representação verbal; Ribeiro (2003), que tratou da habilidade de leitores no meio digital e a transferência de habilidades de leitura do gênero jornal para a navegação no formato digital, bem como a interferência da organização hipertextual na qualidade da leitura; Rouet (1996), que apresentou os variados resultados com relação à leitura dos formatos contínuo e linear; 


\section{DIVERS@!}

Dias (2008), que observou a compreensão e a organização hipertextual. Nesse contexto então, o trabalho se posiciona no foco na observação da organização, conteúdo e natureza do texto e seus impactos nos processos de compreensão leitora, tendo como parâmetros habilidades de leitura baseados nos descritores $\mathrm{SAEB}^{2}$, que são considerados como essenciais também pelo PISA ${ }^{3} \mathrm{O}$ estudo dos processos cognitivos de leituras nesses novos suportes devem ser cada vez mais fomentados, de forma que os conhecimentos sejam aplicados como catalisadores do nosso desenvolvimento cognitivo e cultural.

\section{2 - MATERIAL E MÉTODOS}

Para o experimento, foi utilizado trecho de um curso on-line da área de Redes de Computadores, intitulado "CCNA Exploration 4.0 - Fundamentos de Rede", fornecido pela Instituição Cisco Networking Academy, ligada à empresa norte-americana Cisco Sistems Inc. Desse texto, utilizamos para o nosso experimento parte do Capítulo 1, denominado "Vivendo em um mundo centrado na rede". O texto discorre sobre a influência das redes de computadores no nosso dia a dia e destaca seus insights na nossa vida, estudo, trabalho e diversão.

Validamos esse texto em razão de ter sido projetado com bases em relações hipertextuais (orientada a hiperlinks para navegação entre suas seções, bem como para a significação de termos técnicos) e ser hipermidiático (contendo imagens, esquemas interativos e vídeos). Dessa forma, objetivamos que o leitor fizesse articulações entre as diversas áreas do texto para que construísse uma razoável interpretação. Entretanto, para o nosso propósito, foi necessário que realizássemos adaptações e reescrita de trechos para tornar mais salientes algumas âncoras

2 - Trata-se de uma avaliação nacional em larga escala coordenada pelo Instituto Nacional de Estudos e Pesquisas Educacionais (INEP) e destinada a fornecer informações sobre a qualidade, a equidade e a eficiência da educação básica brasileira, a gestores de sistemas de avaliação, administradores educacionais municipais e estaduais, bem como a professores, visando ao aperfeiçoamento das políticas e dos sistemas de ensino básico (PESTANA, 1998).

3 - Programme for International Student Assessment, exame internacional que se propõe a desenvolver avaliações periódicas em jovens de 15 anos nas áreas de Leitura, Matemática e Ciências em mais de 32 países. Foi elaborado por um consórcio de instituições, lideradas pelo Australian Council for Educational Research no âmbito do programa de educação da Organização para a Cooperação e o Desenvolvimento Econômico (OCDE), organização global que visa a ajudar os governos-membros a desenvolverem políticas nas áreas econômicas e sociais. 


\section{DIVERS@!}

utilizadas na avaliação, como também a supressão de partes, para não estender o texto desnecessariamente nem tornar a leitura morosa em demasia e cansativa para o interlocutor.

Foram organizadas duas versões para este experimento: uma hipertextual e multimodal, com suporte digital, e outra linear, verbal com suporte impresso.

Nesta pesquisa, busca-se identificar como as diferentes configurações da malha textual (linearidade e topologia) modificam o processo de compreensão leitora. A metodologia mais adequada a essa busca é a experimental, em que, de acordo com Cervo (2006), podemos manipular diretamente variáveis que têm relação com o objeto de estudo. Segundo o mesmo autor, nessa metodologia, manipulamos uma variável, aqui chamada de independente, e verificamos a interferência que ela causa em outra variável, chamada dependente, podendo-se, dessa forma, estabelecer uma relação de causa e efeito entre elas. Assim, visamos a identificar a influência da organização e a natureza e conteúdo (variáveis independentes) nos processos de compreensão leitora (variável dependente).

Ainda em Cervo (2006), observa-se a importância da criação de situações de controle, com a finalidade de evitar que variáveis intervenientes possam criar interferências baseadas em informações não contidas no instrumento de investigação e que possam se tornar fatores prevalentes na compreensão. Dessa forma, consideramos como variáveis intervenientes, no caso do experimento do texto científico sobre redes de computadores, o conhecimento técnico prévio ou a experiência laborativa na área de redes de computadores. Para projetar os informantes que pudessem incorrer nessa situação, o formulário de pesquisa contempla esse questionamento. Dessa forma, informantes submetidos ao experimento que tivessem realizado cursos ou trabalho na área de redes de computadores foram excluídos. Para a aplicação da pesquisa, considera-se grupo de controle aquele com tratamento convencional. Esse grupo recebe um gênero textual, do tipo linear, sem os recursos de hipermídia para fins de comparação com os resultados obtidos pelo outro grupo. Este, por sua vez, é submetido a um texto de mesma temática, mas com larga utilização de multimeios. Ambos os grupos responderão a um exame, no qual se pretende verificar e comparar entre eles a capacidade de compreensão na leitura de textos. 


\section{DIVERS@!}

Na observação, considerando uma visão quantitativa, comparamos os resultados, a saber, acertos em questionário aplicado após a leitura de texto em estrutura hipertextual/multimodal, e um outro em estrutura linear, impresso.

As atividades de aplicação dos experimentos se deram, primeiramente, com a subdivisão dos grupos em subgrupos, um submetido ao hipertexto e o outro ao texto convencional. A realização dos experimentos em hipertexto, tanto do grupo 1 como do 2, se deu em laboratórios de informática educacional do IFTO - Campus Palmas. Assim, os alunos submetidos ao experimento em suporte hipertextual utilizaram computadores individuais, e o grupo de controle submetido ao texto linear impresso realizou as atividades em sala de aula convencional. Em ambas as formas, o tempo para a conclusão da atividade não foi limitado.

\section{RESULTADOS E DISCUSSÃO}

\subsection{Resultados Globais}

O questionário de avaliação continha 10 questões, as duas primeiras discursivas, e as outras demais objetivas. Nesse caso, avaliando apenas de forma global, sem enfocar as habilidades, fruto de um próximo tópico, selecionamos nas questões discursivas as respostas avaliadas como pertinentes e verificamos que, ao comparar o resultado nas formas linear e hipertextual, houve uma grande vantagem da versão hipertextual, com índice de $81,8 \%$ sobre a linear, com índice de $66,7 \%$.

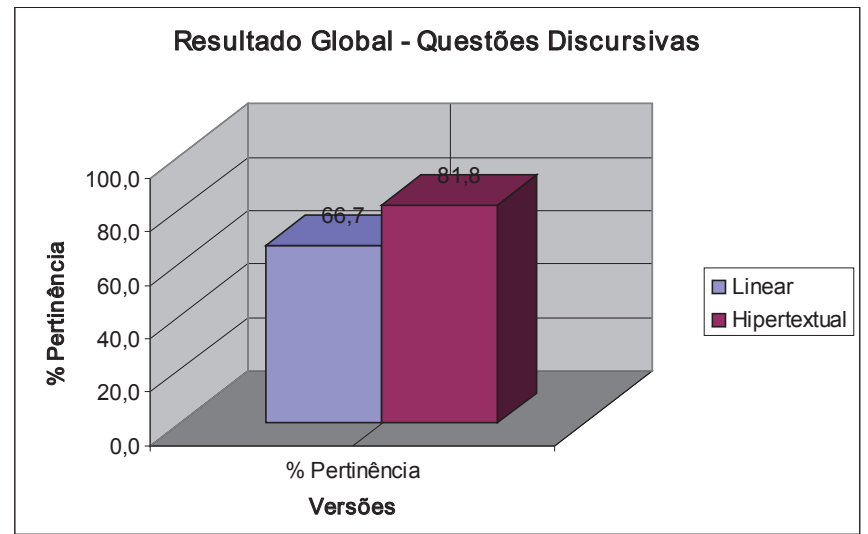

GRÁFICO 1 - RESULTADO GLOBAL - QUESTÕES DISCURSIVAS

FONTE: a autora 


\section{DIVERS@!}

Com relação às questões objetivas do questionário, encontramos resultados nem tanto discrepantes, e o hipertexto sobressaiu levemente com um índice de acertos de 59,1\% sobre o linear, com índice de 56,9\%.

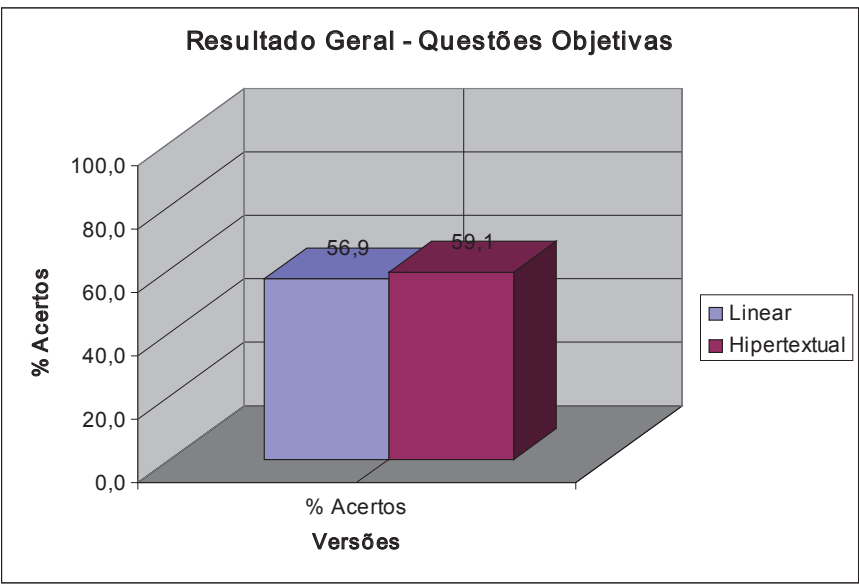

GRÁFICO 2 - RESULTADO GLOBAL - QUESTÕES OBJETIVAS

FONTE: a autora

\subsection{Resultados por Habilidades Leitoras Avaliadas}

O questionário encaminhado aos informantes continha 10 questões, que tinha por objetivo avaliar, conforme descrito na metodologia, 5 habilidades leitoras, a saber: produção de inferência, compreensão global, localização de informação explícita, relações de coerência entre os links, relações de coerência local, e 2 questões para cada habilidade. Para apresentar esses dados, agrupamos o conjunto de acertos/pertinências por habilidades.

Foram avaliadas nas questões 1 e 10 a habilidade de produção de inferências. Contabilizando-se as questões classificadas como pertinentes/corretas, encontramos uma vantagem da versão hipertextual sobre a versão linear, com os respectivos índices de 81,8\% e $66,7 \%$.

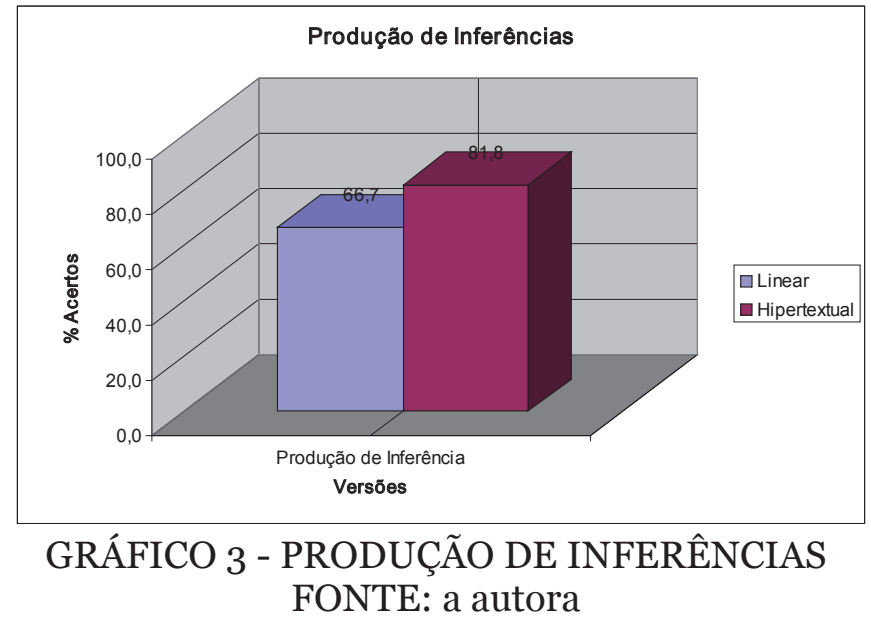

Divers@ Revista Eletrônica Interdisciplinar/Matinhos/Vol.6, n.1, p.1-73/jan./jun./2013 ISSN 1983-8921 
Já a habilidade de compreensão global, ao contrário da anterior, mostra o texto linear com índice de acertos na ordem de 66,7\%, sobressaindo-se sobre o hipertextual, que contabilizou índice de 59,1\%.

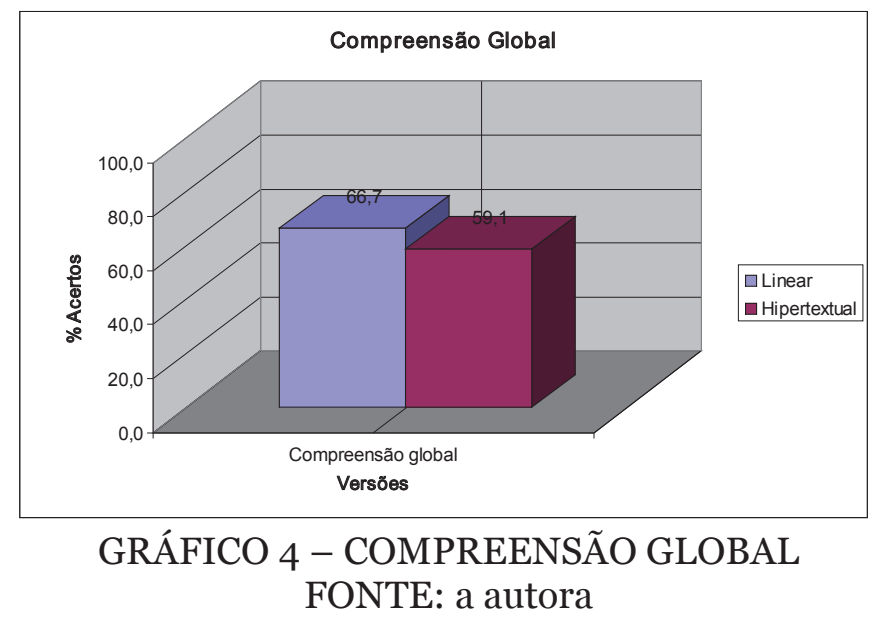

A habilidade de localização de informação explícita foi a habilidade que mostrou maior discrepância nos índices de acertos nessa versão do experimento. A versão linear foi a que apresentou melhores resultados, com 61,1\% de acertos contra 40,9\% apresentados na versão hipertextual

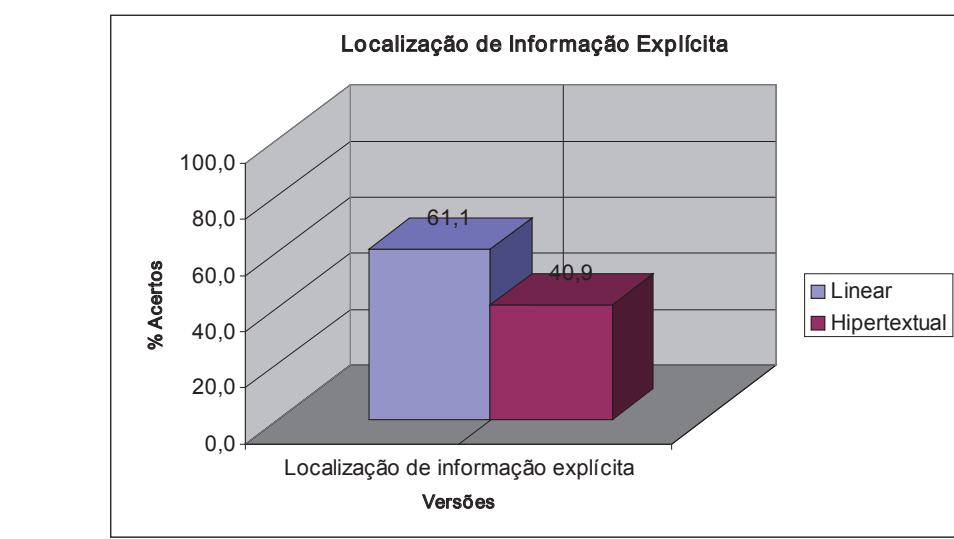

\section{GRÁFICO 5 - LOCALIZAÇÃO DE INFORMAÇÃO EXPLÍCITA} FONTE: a autora

Quanto ao estabelecimento de relações de coerência entre os links, voltamos a verificar a vantagem do hipertexto sobre a linear, que apresenta índices de 59,1\% e 44,4\%. 


\section{DIVERS@!}

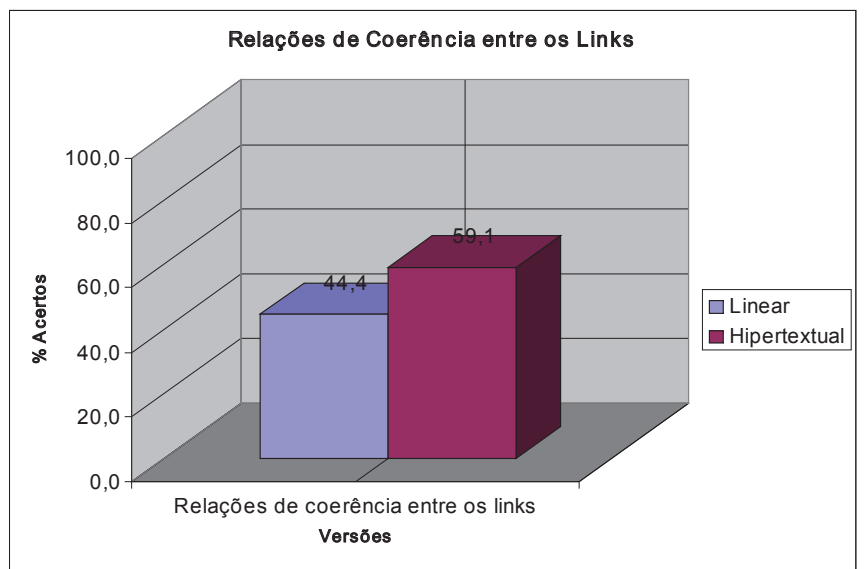

GRÁFICO 6 - RELAÇÕES DE COERÊNCIA ENTRE OS LINKS

FONTE: a autora

Finalmente, com respeito à habilidade de estabelecimento de relações de coerência local, continuam os resultados favoráveis à versão hipertextual do experimento, ao atingir nesse quesito o índice de 77,3\% frente aos 55,6 apresentados na versão linear.

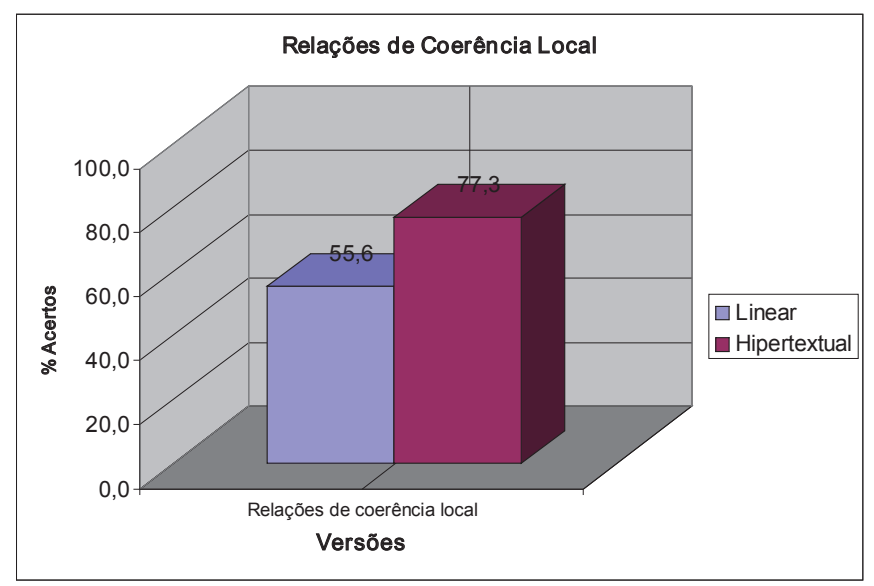

GRÁFICO 7 - RELAÇÕES DE COERÊNCIA LOCAL FONTE: a autora

A facilidade de uso dos links pop-up's na versão hipertextual pode explicar um maior índice de acertos na habilidade de estabelecimento de coerência entre os links, em contraposição a uma opcionalidade e menor usabilidade do glossário embutido ao final do texto linear verificada no experimento. 


\section{DIVERS@!}

\section{4 - CONSIDERAÇÕES FINAIS}

Os resultados da análise quantitativa não comprovaram, na comparação dos índices de acertos nas respostas dos informantes, a ocorrência de um padrão de comportamento que pudesse ser atribuído às diferenças nas organizações textuais linear e hipertextual.

Ao observarmos a sequência de acesso aos links após a retirada dos retornos ou repetições, observamos que em ambos os experimentos todos os informantes reproduziram em seu trajeto de leitura a mesma sequência sugerida no texto. Dessa forma, apesar da malha hipertextual permitir e facilitar a quebra dessa sequência, os leitores em termos de novidade da informação continuaram a ter uma leitura linear, de forma análoga à leitura de um texto impresso. Acreditamos que a razão dessa forma de leitura linear, apesar dos recursos oferecidos pelos novos suportes, deva-se ao modelo cultural das nossas práticas de leitura, ainda fortemente arraigadas.

Surgiram, com o amadurecimento deste trabalho, algumas questões que necessitam de novos estudos, relacionados ao uso do hipertexto, como a observação através de textos de diferentes naturezas (temáticas), bem como a investigação da causa das repetições e retrocessos durante a prática da leitura.

\section{REFERÊNCIAS}

CERVO, Amado L.; BERVIAN, Pedro A.; SILVA, Roberto da. Metodologia Científica. 6. ed. São Paulo: Pearson Prentice Hall, 2006.

COSCARELLI, Carla Viana; RIBEIRO, Ana Elisa. Letramento digital. Aspectos sociais e possibilidades pedagógicas. Belo Horizonte: Autêntica, 2005, p. 4158.

DIAS, Marcelo Cafiero. A Influência do Modo de Organização de Hipertextos na Compreensão: Dissertação (Mestrado em Estudos Linguísticos) - Faculdade de Letras, UFMG, 2008.

KLEIMAN, Ângela. Texto e leitor: aspectos cognitivos da leitura. 9. ed. Campinas: Pontes, 2004.

MARCUSCHI, Luiz Antônio. Cognição, Linguagem e Práticas Interacionais. Rio de Janeiro: Lucerna, 2007.

Linearização, cognição e referência: o desafio do hipertexto. Línguas e instrumentos linguísticos, n. 3 . Campinas (SP): Pontes, 1999, p.21-45.

(79-111).

. O hipertexto como um novo espaço de escrita em sala de aula. In: Linguagem \& Ensino, v. 4, No. 1, 2001

Ribeiro, C. (2003). Metacognição: um apoio ao processo de aprendizagem. Reflexão e Critica, .16(1), 109-116 